\title{
Sphaerodactylus elegans (Ashy Sphaero).
}

\section{Distribution.}

Date of observation: 19 July 2010. Location: Haiti: Sud; 3 km N Port Salut. Coordinates: 18.10913, -73.94302. Elevation: 9 m. Voucher: image. Unpatterned adults of this species were seen active on the wall of a hotel at night, around lights. The species is known from throughout the Tiburon peninsula of Haiti and therefore this locality record is not unexpected. Accompanied by Richard Thomas. Thanks to Philippe Bayard and the Audubon Society of Haiti.

S. Blair Hedges, Pennsylvania State University, Department of Biology, 208 Mueller Lab, University Park, Pennsylvania, 16802, USA, sbh1@psu.edu.

Citation: Hedges SB. 2010. Sphaerodactylus elegans

(Ashy Sphaero). Distribution. Caribbean Herpetology 4:1.

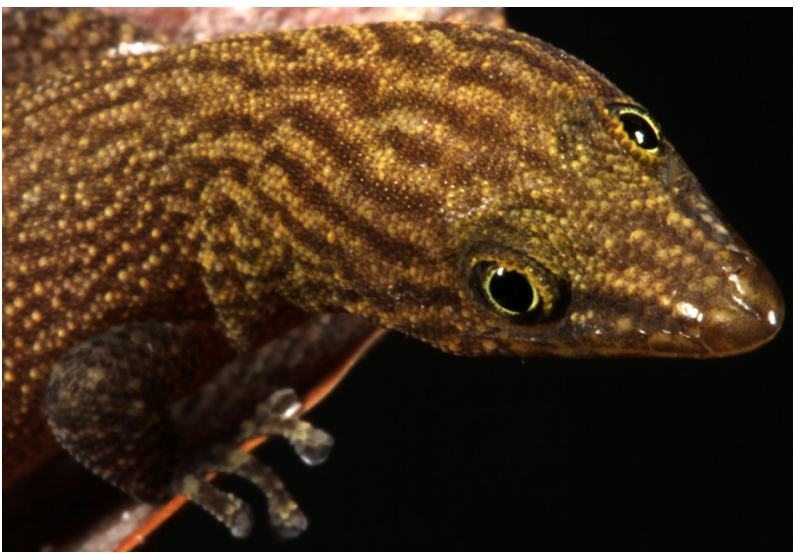

Photograph by SB Hedges

Published online 26 August 2010 